\title{
Pembelajaran Seni Budaya Indonesia dalam Nuansa Interkultural Program Internasional "Darmasiswa" di Sekolah Tinggi Seni Indonesia (STSI) Bandung
}

\author{
Enok Wartika, Yanti Heriyawati \\ Institut Seni Budaya Indonesia (ISBI) Bandung \\ Jl. Buah Batu No. 212 Bandung 40265
}

\begin{abstract}
STSI Bandung is one of the higher education institutions participating in the government's program of international cultural promotion "Darmasiswa". "Darmasiswa" is a program of cultural diplomacy aims at improving cooperation with countries which have diplomatic relationships with Indonesia and promoting good image of Indonesia among people of other countries. This paper is a study of transfer process of art learning in the cultural diversity of the "Darmasiswa" participants. This study used a qualitative approach with the case study method. The complexities of multicultural interaction are found in the process. Those complexities include trans-cultural communication, international communication and cross-cultural communication. Multicultural arts learning process is delivered in a variety of learning methods. Attractiveness and uniqueness of the art teaching materials is a force that can help to bridge any cultural differences among the participants of the international student program.
\end{abstract}

Keywords: darmasiswa, intercultural communication, promotion, culture

\begin{abstract}
ABSTRAK
STSI Bandung merupakan salah satu lembaga pendidikan tinggi yang berpartisipasi dalam program promosi budaya internasional pemerintah "Darmasiswa". "Darmasiswa" adalah program di bawah diplomasi kebudayaan yang tujuannya untuk lebih meningkatkan hubungan kerja antar negara, sekaligus guna menanamkan image yang baik tentang Indonesia di mata dunia. Tulisan ini merupakan hasil penelitian terhadap proses penyelenggaraan program "Darmasiswa" dalam mentransfer pembelajaran seni Indonesia yang pesertanya memiliki keberagaman latar belakang budaya. Penelitian ini menggunakan pendekatan kualitatif dengan metode studi kasus. Di dalam prosesnya ditemukan hal menarik yaitu kompleksitas interaksi multikultural di antaranya; komunikasi interkultural, komunikasi internasional, dan komunikasi lintas budaya. Proses pembelajaran seni bernuansa multikultural ini telah memadukan berbagai metode pembelajaran. Daya tarik dan keunikan materi ajar kesenian, diharapkan mampu membantu menjembatani segala perbedaan budaya di antara mahasiswa internasional.
\end{abstract}

Kata kunci: Darmasiswa, komunikasi interkultural, promosi, budaya 


\section{PENDAHULUAN}

Indonesia adalah negara yang memiliki keunikan dan pesona kebudayaan yang melimpah baik yang bersifat material maupun imaterial. Kekayaan budaya yang ada sesungguhnya merupakan potensi yang sangat besar untuk mengangkat keluhuran martabat bangsa Indonesia di dunia internasional. Banyak program promosi budaya dilakukan pemerintah Indonesia misalnya; misi-misi kebudayaan, promosi pariwisata, festival kebudayaan, seminar dan lokarya budaya serta melalui program-program yang dikemas melalui dunia pendidikan.

Khusus promosi budaya melalui program pendidikan yang berskala internasional, penulis tertarik untuk menelaah salah satu di antaranya yaitu mengenai program "Darmasiswa". "Darmasiswa" adalah program biro kerja sama luar negeri dari Departemen Pendidikan Nasional RI bekerja sama dengan Departemen Luar Negeri di bawah payung diplomasi kebudayaan yang tujuannya untuk lebih meningkatkan hubungan kerja antar negara, sekaligus guna menanamkan image yang baik tentang Indonesia di mata dunia. Penyelenggaraan ini ditawarkan ke sejumlah perguruan Tinggi, salah satu di antaranya adalah STSI yang sejak tanggal 6 Oktober 2014 telah berubah menjadi Institut Seni Budaya Indonesia (ISBI) Bandung. Sejak tahun 2000, STSI Bandung dipercaya menjadi salah satu Perguruan Tinggi untuk mengelola peserta "Darmasiswa" RI yang datang dari berbagai benua; Amerika, Asia, Eropa, Afrika dan Australia di mana mereka dikondisikan untuk mempelajari budaya nusantara khususnya seni budaya yang berasal dari Jawa Barat.

Pengelolaan mahasiswa "Darmasiswa" di STSI/ISBI Bandung merupakan tantangan dan juga peluang untuk berkontribusi menyukseskan program pemerintah pusat meningkatkan reputasi Indonesia di du- nia internasional. Suatu kesempatan untuk mengembangkan proses pembelajaran seni bernuansa multikultural yang memiliki solidaritas dan toleransi di antara peserta. Kepercayaan pemerintah idealnya menjadikan STSI/ISBI Bandung sebagai aktor pelaku komunikasi lintas budaya dan komunikasi internasional yang mampu menjalankan programnya dengan baik. Apalagi konten promosi dan pembelajaran yang diusungnya berkaitan dengan masalah kebudayaan.

Namun, penyelenggaraan program-program budaya berskala internasional memerlukan persiapan matang dengan dukungan berbagai sumber daya yang memadai. Jika tidak, alih-alih menjadi kampus penyelenggara promosi seni budaya yang handal tetapi bukan tidak mungkin malah akan memberi jejak image negatif terhadap peserta mahasiswa internasional yang menimba ilmu di kampus seni ini. Pertanyaannya adalah, mampukah tim pengelola program "Darmasiswa" di STSI/ISBI Bandung menjadi komunikator-komunikator interkultural yang melakukan pentransferan pembelajaran seni bagi mahasiswa internasionalnya? Dan bagaimana cara mengatasi berbagai perbedaan dan hambatan-hambatan komunikasi yang muncul? Inilah yang akan ditelaah dalam uraian tulisan ini.

\section{METODE}

Setiap penelitian membutuhkan metodologi tertentu disesuaikan dengan kebutuhan untuk pengumpulan dan pengolahan data, penganalisaan, identifikasi masalah, implikasi, antisipasi dan juga menginterpretasikan data untuk mencapai tujuan penelitian yang akan dicapai. Adapun pendekatan yang digunakan dalam penelitian ini adalah kualitatif dengan metode penelitian studi kasus.

Penggunaan metode studi kasus karena peneliti berupaya untuk memusatkan diri pada suatu unit tertentu dari berbagai 
fenomena. Metode studi kasus digunakan agar mendapatkan data penelitian yang sifatnya mendalam dan menusuk sasaran penelitian. Peneliti melakukan eksplorasi berkaitan dengan berbagai hal mengenai aktivitas pembelajaran yang dilakukan tim pengelola program internasional terhadap mahasiswa peserta "Darmasiswa" STSI/ISBI Bandung yang datang dari berbagai perbedaan latar belakang budaya.

\section{HASIL DAN PEMBAHASAN}

\section{Darmasiswa Salah Satu Program Diplomasi Budaya Melalui Bidang Pendidikan}

Darmasiswa adalah program biro kerja sama luar negeri dari Departemen Pendidikan Nasional RI bekerja sama dengan Departemen Luar Negeri di bawah payung diplomasi kebudayaan yang tujuannya guna lebih meningkatkan hubungan kerja antar negara, sekaligus guna menanamkan image yang baik tentang Indonesia di mata dunia. Selain itu juga bertujuan untuk memperkuat jalinan budaya dan saling pengertian di antara para peserta. Program beasiswa Darmasiswa ditawarkan kepada semua siswa yang berasal dari negara-negara yang memiliki hubungan diplomatik dengan Indonesia untuk mempelajari bahasa dan berbagai kesenian nusantara. Para peserta akan memilih salah satu dari 45 universitas yang telah ditunjuk oleh Departemen Pendidikan Republik Indonesia.

Program Darmasiswa terdiri dari dua bentuk yaitu; beasiswa reguler untuk satu tahun dan program reguler untuk enam bulan. Program ini telah dimulai sejak tahun 1974 yang semula hanya merupakan bagian dari kerjasama di antara negara-negara ASEAN. Awal tahun 90-an diperluas dan ditawarkan kepada semua negara yang memiliki hubungan diplomatik, dan sampai saat ini jumlah negara yang berpatisipasi dalam program ini berjumlah 75 negara.
Menyimak dari tujuan diselenggarakannya program ini, di dalamnya terjadi proses komunikasi internasional karena melibatkan kerjasama antar negara-negara yang telah memiliki hubungan diplomatik dengan Indonesia. Menurut (Rakhmat dkk, 1993: v) komunikasi internasional adalah komunikasi yang dilakukan antara komunikator dari suatu negara untuk menyampaikan pesan-pesan yang berkaitan dengan berbagai kepentingan negaranya kepada komunikate yang mewakili negara lain dengan tujuan untuk memperoleh dukungan yang lebih luas.

Kemudian dalam prosesnya yang melibatkan berbagai etnik, ras dan antar bangsa yang notabene beraneka budayanya maka program Darmasiswa tidak saja melibatkan komunikasi internasional tetapi juga bisa dikatakan melakukan berbagai proses komunikasi lain yaitu; komunikasi antar ras, antarbudaya dan lintas budaya.

Pemahaman konsep antarbudaya, dalam aplikasinya sering dipertukarkan dengan komunikasi lintas budaya, komunikasi antar etnik, komunikasi antar ras dan komunikasi internasional. Deddy Mulyana (2001: v) mengemukakan; komunikasi antarbudaya sebenarnya lebih inklusif daripada antar etnik atau antar ras karena bidang yang dipelajarinya tidak sekedar antara dua kelompok etnik atau ras tetapi lebih informal, personal dan tidak selalu bersifat antar bangsa, berbeda dengan komunikasi internasional yang cenderung mempelajari komunikasi antar bangsa lewat saluran-saluran formal dan media massa. Interkultural melibatkan komunikasi di antara orang-orang yang berbeda budaya dengan melibatkan media.

Terlepas dari berbagai kajian definisi yang penjabarannya memiliki banyak kesamaan, pada intinya program darmasiswa dengan peserta yang sangat variatif latar belakang budayanya memiliki potensi yang kuat untuk dikembangkan. Dilihat dari berbagai kajian komunikasi dalam pemba- 
hasan tulisan ini akan dititikberatkan pada bagaimana terciptanya suatu harmoni di antara orang-orang yang berbeda budayanya sehingga mereka mampu menjadi manusia yang sama-sama memiliki motivasi untuk mempelajari berbagai keunikan seni budaya Indonesia. Hasilnya diharapkan dapat membentuk citra positif tentang Indonesia, karena pada hakekatnya setiap peserta yang datang dari manca negara adalah penyambung lidah/duta Indonesia untuk menyampaikan apa dan bagaimana sesungguhnya Indonesia. Artinya program ini harus dikelola secara baik, benar dan profesional.

\section{Tantangan dan Peluang dalam Menyukseskan Program Darmasiswa di STSI/ISBI Bandung}

Setiaptahun, STSI/ISBI Bandung rata-rata menerima sekitar 12 mahasiswa mancanegara yang secara khusus tertarik mempelajari berbagai kesenian pertunjukan tradisional nusantara yang meliputi; tari tradisional, musik-musik tradisional, teater rakyat dan kerajinan rakyat. Dalam pelaksanaannya para peserta diberi kesempatan untuk bergaul secara luas dengan berbagai unsur yang ada di lingkungan STSI/ISBI Bandung. Mereka diberi kesempatan untuk bergabung belajar bersama dengan mahasiswa regular disamping diwajibkan mengikuti paket program pembelajaran khusus untuk peserta mahasiswa "Darmasiswa". Pada bulan-bulan awal kedatangan, mereka diberi pelatihan intensif bahasa Indonesia untuk membantu memperlancar program pembelajaran sehingga waktu mereka lebih efektif untuk mempelajari budaya Indonesia.

Berbagai upaya untuk memadukan perbedaan dilakukan, mengingat karakteristikkarakteristik budaya yang telah melekat pada masing-masing peserta harus dapat dikonstruksi menjadi sesuatu yang lentur tanpa menyinggung perasaan para pemiliknya. Artinya pengelola program Darmasiswa ini harus mampu mengembangkan pola komunikasi di antara peserta agar mereka bisa saling menghormati, saling memahami dan menghargai berbagai perbedaan sehingga kesalahpahaman dapat dikurangi. Pola komunikasi yang dikembangkan mengarah pada upaya menciptakan suasana kelompok manusia antarbudaya yang bisa berinteraksi dengan nyaman walaupun berbeda dalam banyak hal.

Selama program berlangsung banyak terjadi hambatan yang disebabkan; motivasi yang beragam, bahasa yang berbeda, kebiasaan yang bertolak belakang, karakteristik personal yang berlainan, cara berfikir yang tidak sama dan lain-lain. Semua itu merupakan hal-hal yang dapat memicu permasalahan yang kerap muncul selama proses belajar berjalan. Hal ini terutama terlihat manakala mereka dituntut untuk menghasilkan sebuah karya kolektif yang melibatkan kerjasama. Masalah lain juga muncul ketika staf pengajar memiliki kemampuan terbatas dalam penguasaan bahasa internasional sehingga menghambat proses pembelajaran. Konflik sering terjadi dan tak terhindarkan karena ego dari para peserta walaupun akhirnya masalah ini dapat diselesaikan.

Keberagaman peserta, sangat terlihat dari cara mereka berperilaku. Seringkali menerapkan pola pikir mereka di negara asalnya tanpa cukup mempertimbangkan keselarasannya dengan konteks budaya setempat atau dengan sesama peserta. Kress (dalam Mulyana, 2010:3) mengungkapkan bahwa "tak mungkin" memikirkan komunikasi tanpa memikirkan konteks dan makna kulturalnya. Konteks budaya yang dimaksud terlihat pada tabel 1 .

Karakteristik-karakteristik budaya pasti akan mewarnai tata cara mereka bersikap. Di satu sisi karakteristik tersebut menjadi hambatan untuk kesuksesan program tetapi di sisi lain merupakan tantangan untuk memaksimalkan upaya mengatasi berbagai perbedaan. Hal ini sesuai dengan ungkapan Philip R. Harris \& Robert T. Moran (dalam 


\begin{tabular}{|c|c|c|}
\hline $\begin{array}{l}\text { Faktor- } \\
\text { faktor }\end{array}$ & $\begin{array}{l}\text { High-context } \\
\text { culture }\end{array}$ & $\begin{array}{l}\text { Low-context } \\
\text { culture }\end{array}$ \\
\hline $\begin{array}{l}\text { pola ko- } \\
\text { munikasi }\end{array}$ & $\begin{array}{l}\text { banyak meng- } \\
\text { gunakan metafor, } \\
\text { pesan-pesan yang } \\
\text { implisit, tidak "to } \\
\text { the point" }\end{array}$ & $\begin{array}{l}\text { pesan yang di- } \\
\text { sampaikan to the } \\
\text { point, tidak "ber- } \\
\text { putar-putar" }\end{array}$ \\
\hline $\begin{array}{l}\text { sikap diri } \\
\text { apabila } \\
\text { terjadi ke- } \\
\text { salah-an }\end{array}$ & $\begin{array}{l}\text { menerima/ } \\
\text { meyikapi kesalah- } \\
\text { an yang terjadi } \\
\text { sebagai kesalahan } \\
\text { pribadi, cende- } \\
\text { rung untuk } \\
\text { menginternalisasi } \\
\text { banyak hal. }\end{array}$ & $\begin{array}{l}\text { menilai kesalah- } \\
\text { an terjadi karena } \\
\text { faktor eksternal/ } \\
\text { orang lain. }\end{array}$ \\
\hline $\begin{array}{l}\text { peng- } \\
\text { gunaan } \\
\text { komuni- } \\
\text { kasi non } \\
\text { verbal }\end{array}$ & $\begin{array}{l}\text { menggunakan } \\
\text { komunikasi non- } \\
\text { verbal dengan } \\
\text { ekstensif. }\end{array}$ & $\begin{array}{l}\text { cenderung untuk } \\
\text { menggunakan } \\
\text { komunikasi verbal } \\
\text { daripada non-ver- } \\
\text { bal. }\end{array}$ \\
\hline ekspresi & $\begin{array}{l}\text { cenderung, ilmu } \\
\text { padi (semakin } \\
\text { berisi sema- } \\
\text { kin merunduk } \\
\text { - rendah hati). } \\
\text { Menyembunyikan }\end{array}$ & $\begin{array}{l}\text { ekspresif, kalau } \\
\text { tidak suka/tidak } \\
\text { setuju terhadap } \\
\text { sesuatu akan di- } \\
\text { sampaikan, tidak } \\
\text { dipendam. }\end{array}$ \\
\hline $\begin{array}{l}\text { orientasi } \\
\text { terhadap } \\
\text { kelompok }\end{array}$ & $\begin{array}{l}\text { ada pemisahan } \\
\text { yang jelas an- } \\
\text { tara ini kelom- } \\
\text { pok saya VS itu } \\
\text { bukan kelompok } \\
\text { saya. }\end{array}$ & $\begin{array}{l}\text { terbuka, tidak teri- } \\
\text { kat dalam dengan } \\
\text { satu kelompok, } \\
\text { bisa berpindah- } \\
\text { pindah sesuai ke- } \\
\text { butuhan/konteks. }\end{array}$ \\
\hline $\begin{array}{l}\text { ikatan } \\
\text { kelompok }\end{array}$ & $\begin{array}{l}\text { memiliki ikatan } \\
\text { kelompok yang } \\
\text { sangat kuat, baik } \\
\text { itu keluarga, ke- } \\
\text { lompok masyara- } \\
\text { kat, dsb. }\end{array}$ & $\begin{array}{l}\text { cenderung untuk } \\
\text { tidak memiliki } \\
\text { ikatan kelompok } \\
\text { yang kuat - lebih } \\
\text { individuil. }\end{array}$ \\
\hline $\begin{array}{l}\text { komitmen } \\
\text { terhadap } \\
\text { hubung- } \\
\text { an dengan } \\
\text { sesama }\end{array}$ & $\begin{array}{l}\text { komitmen yang } \\
\text { tinggi terhadap } \\
\text { hubungan jangka } \\
\text { panjang-hubung- } \\
\text { an baik lebih pen- } \\
\text { ting daripada } \\
\text { tugas/pekerjaan. }\end{array}$ & $\begin{array}{l}\text { komitmen yang } \\
\text { rendah terhadap } \\
\text { hubungan antar } \\
\text { sesama - tugas/ } \\
\text { pekerjaan lebih } \\
\text { penting daripada } \\
\text { hubungan baik. }\end{array}$ \\
\hline $\begin{array}{l}\text { fleksibili- } \\
\text { tas } \\
\text { terhadap } \\
\text { waktu }\end{array}$ & $\begin{array}{l}\text { waktu bukanlah } \\
\text { sebuah titik, me- } \\
\text { lainkan sebuah } \\
\text { garis - proses } \\
\text { lebih penting } \\
\text { daripada hasil } \\
\text { akhir. }\end{array}$ & $\begin{array}{l}\text { waktu adalah } \\
\text { sebuah titik yang } \\
\text { apabila tidak } \\
\text { dimanfaatkan } \\
\text { dengan baik, akan } \\
\text { terbuang percuma } \\
\text { - hasil akhir lebih } \\
\text { penting daripada } \\
\text { proses. }\end{array}$ \\
\hline
\end{tabular}

Tabel 1

Diadaptasi dari model budaya

Prof. Edward T. Hall, seorang antropolog dari Columbia University AS
Mulyana, 2001: 58-62) mengungkapkan bahwa:

"budaya memberi identitas pada sekelompok orang, bagaimana kita mengidentifikasi aspek-aspek budaya yang menjadikan sekelompok orang berbeda dengan kelompok lainnya harus dilihat dari aspek-aspeknya yang meliputi:

a. Komunikasi dan bahasa

b. Pakaian dan penampilan.

c. Makanan dan kebisaaan makan.

d. Waktu dan keselarasan akan waktu.

e. Penghargaan dan pengakuan.

f. Hubungan-hubungan.

g. Nilai dan norma.

h. Rasa diri dan ruang.

i. Proses mental dan belajar.

j. Kepercayaan dan sikap."

Faktanya memang mengelola kumpulan orang-orang yang berbeda untuk dijadikan sebuah kumpulan manusia yang memiliki toleransi tinggi memerlukan strategi tersendiri. STSI/ISBI Bandung, dianggap telah mampu memadukan keberagaman yang ada melalui pendekatan para pembina. Strategi pembelajaran seni yang dikembangkan, misalnya: 1) memadukan para peserta yang memiliki konteks budaya tinggi dan konteks budaya rendah dengan pendekatan budaya Indonesia (khususnya Jawa Barat); 2) mengupayakan banyak diskusi saling terbuka dalam topik-topik yang berkaitan dengan kesenian yang akan mereka pelajari; 3) membiasakan latihan kesenian dan mengembangkan kerja sama dalam konsep kesetaraan, dimana ide-ide untuk mengerjakan suatu karya datangnya harus bergiliran dari para peserta dan anggota kelompok lain dituntut untuk mendukung dan memperkaya.

Bahasa selama proses pembelajaran yang digunakan, dianjurkan menggunakan bahasa Indonesia dan atau bahasa Inggris. Hal ini dimaksudkan untuk mengurangi tingkat miskomunikasi dan "culture shock" di antara para peserta jika kemampuan untuk berkomunikasi sangat minim. Untuk membina kekompakan di sela-sela waktu luang mereka sering diajak nonton pertunjuk- 
an aneka ragam kesenian nusantara untuk memberi apresiasi, atau berdarmawisata ke tempat-tempat wisata arkeologi atau wisata alam untuk memperkaya pengetahuan tentang kekayaan budaya Indonesia. Prinsipnya diupayakan untuk memberikan kesan yang baik walaupun langkah-langkah yang ditempuh juga tidak seutuhnya dapat sesuai dengan kemauan mereka yang beragam.

Para peserta darmasiswa yang belajar beraneka macam kesenian tradisional Indonesia umumnya mampu menyerap materi pembelajaran. Biasanya mereka aktif memanfaatkan waktu belajarnya selama setahun waktu tinggal mereka di Indonesia. Hal ini terlihat dari tingkat penguasaan mereka terhadap beberapa tarian dan mampu memainkan beberapa alat musik tradisional bahkan berkolaborasi dengan mahasiswa reguler. Selain tingkat keaktifan mereka juga disebabkan materi pembelajaran kesenian yang lebih banyak praktek daripada materi yang besifat teoritis. Mereka memiliki banyak kesempatan untuk melihat, mendengar, merasa, menyentuh dan mempraktekannya.

Kesenian memilikikelebihan dalam menjembatani berbagai perbedaan mengingat seni lebih didominasi oleh unsur rasa yang mengutamakan unsur estetika. Kebutuhan manusia untuk mengungkapkan perasaan keindahan kelihatannya berlaku sejak lama dan bersifat universal. Hasil-hasil penelitian lintas budaya dan prasejarah pada aneka ragam kebudayaan telah menunjukan bukti-bukti bahwa tidak ada kebudayaan yang pernah kita kenal yang di dalamnya tidak menampung bentuk-bentuk dari ekspresi estetik. Ini menunjukan bahwa betapapun sederhananya kehidupan manusia, di selasela memenuhi kebutuhan primernya mereka senantiasa mencari peluang untuk memenuhi hasratnya dalam mengungkapkan dan memanfaatkan keindahan (Badcock dalam Rohidi, 2000: 17). Kesenian telah menyertai kehidupan manusia sejak awal kehidupannya, semua menunjukan keunikan kesenian baik dilihat dari umurnya maupun keuniversalannya sebagai salah satu bagian dari kebudayaan. (Cassirer, dalam Koentjaraningrat, 1979: 217).

Dengan demikian, dapat dikatakan bahwa setiap masyarakat baik secara sadar-maupun tidak sadar mengembangkan kesenian sebagai ungkapan dan pernyataan rasa estetis yang merangsangnya sejalan dengan pandangan, aspirasi, kebutuhan dan gagasangagasan yang mendominasinya. Mengingat kelenturan kesenian inilah menurut kajian penulis yang menyebabkan pola komunikasi interkultural mahasiswa Darmasiswa mudah dipadukan. Unsur rasa ketika berkarya dapat mambantu membuat pola komunikasi menjadi lebih halus dan humanis. Mereka bisa menjalaninya dengan suka cita karena selama proses pembelajaran ditanamkan bahwa yang namanya kesenian proses apresiasinya adalah milik setiap individu. Setiap orang berhak menyatakan indah atau tidak terhadap suatu objek seni dan tidak perlu diperdebatkan kecuali berargumen untuk memperluas wawasan yang tujuannya tentu bukan untuk saling menyalahkan tetapi untuk saling memperkaya pemahaman mengenai esensi seni itu sendiri.

Disetiap kesempatan para peserta dikondisikan untuk melakukan apresiasi seni yaitu penikmatan, penghargaan dan pemahaman terhadap suatu hasil karya seni. Dengan demikian menurut Saini KM, mengapresiasi berarti menikmatinya dan menghargainya mengapa kita bersikap positif terhadap sebuah karya seni. (2001: 5).

Adapun proses pembelajaran senibudaya bagi mahasiswa internasional "Darmasiswa" yang dikelola STSI/ISBI Bandung didesain dalam beberapa tahapan program. Secara garis besar dapat dilihat pada bagan 1 .

Paket Materi Perkuliahan untuk mahasiswa "Darmasiswa" STSI/ISBI Bandung yang telah dirancang penyusun kurikulum dapat dilihat pada tabel 2 dan tabel 3. 


\begin{tabular}{|c|c|c|c|c|c|c|}
\hline \multicolumn{2}{|c|}{$\begin{array}{l}\text {-Pembekalan } \\
\text { terpusat di } \\
\text { Jakarta } \\
\text { - penjemputan } \\
\text { oleh TimSTSI } \\
\text { Bandung } \\
\text {-Penempatan/p } \\
\text { engaturan } \\
\text { tempattinggal } \\
\text {-Pengurusan } \\
\text { administrasi } \\
\text { ijin tinggal }\end{array}$} & \multicolumn{2}{|c|}{$\begin{array}{l}\text {-Penerimaan } \\
\text { resmi } \\
\text {-Pengenalan } \\
\text { kampus } \\
\text {-intensif } \\
\text { pembelajaran } \\
\text { Bahasa } \\
\text { Indonesia }\end{array}$} & $\begin{array}{l}\text { •perkuliahan } \\
\text { semester 1. Mata } \\
\text { kuliah disesuaikan } \\
\text { dengan program } \\
\text { studi yang dipilih. di } \\
\text { akhir semester } \\
\text { mengadakan } \\
\text { pertunjukan untuk } \\
\text { mengevaluasi } \\
\text { keberhasilan } \\
\text { program }\end{array}$ & $\begin{array}{l}\text { Semester 2:Mata } \\
\text { kuliah sesuai paket. } \\
\text { diakhir semester } \\
\text { mengadakan } \\
\text { pertunjukan untuk } \\
\text { mengevaluasi } \\
\text { keberhasilan } \\
\text { program }\end{array}$ & $\begin{array}{l}\text {-Program satu tahun } \\
\text { selesai. Melakukan } \\
\text { kolaborasi bersama } \\
\text { seluruh Darmasiswa } \\
\text { se-Indonesia. } \\
\text {-Peserta } \\
\text { dikembalikan ke } \\
\text { pusat untuk } \\
\text { pengurusan } \\
\text { kepulangan ke } \\
\text { negara masing- } \\
\text { masing }\end{array}$ \\
\hline \multicolumn{2}{|c|}{$\begin{array}{l}\text { Tahap 1: awal } \\
\text { kedatangan }\end{array}$} & & & Tahap & & $\begin{array}{l}\text { Ianap s: aknir } \\
\text { program }\end{array}$ \\
\hline \multicolumn{7}{|c|}{$\begin{array}{l}\text { Bagan } 1 \\
\text { belajaran seni budaya mahasiswa internasional } \\
\text { STSI/ISBI bandung }\end{array}$} \\
\hline No. & \multicolumn{2}{|c|}{ Materi } & \multicolumn{4}{|c|}{ Deskripsi } \\
\hline 1 & \multicolumn{2}{|c|}{ Bahasa Indonesia } & \multicolumn{4}{|c|}{$\begin{array}{l}\text { Memberikan keterampilan dasar berkomunikasi dalam bahasa } \\
\text { Indonesia. }\end{array}$} \\
\hline 2 & \multicolumn{2}{|c|}{ Kebudayaan Sunda } & \multicolumn{4}{|c|}{$\begin{array}{l}\text { Memberikan wawasan tentang prinsip-prinsip dasar budaya orang } \\
\text { Sunda. }\end{array}$} \\
\hline
\end{tabular}

Tabel 2

Kurikulum Institusi

\begin{tabular}{|c|l|l|}
\hline No. & \multicolumn{1}{|c|}{ Materi } & \multicolumn{1}{c|}{ Deskripsi } \\
\hline $\begin{array}{c}\text { Program Studi Seni Tari: } \\
1\end{array}$ & Teknik Tari & Mempelajari teknik-teknik dasar gerak tari \\
2 & Topeng Cirebon (Klana) & Mempelajari teknik-teknik dasar gerak tari Topeng Cirebon \\
3 & Tari Rakyat & Mempelajari teknik-teknik dasar gerak tari Rakyat \\
4 & Jaipongan & Mempelajari teknik-teknik dasar gerak tari Jaipongan \\
5 & Pencak Silat & Mempelajari teknik-teknik dasar gerak tari Pencak Silat \\
Program Studi Seni Karawitan: & \\
& Suling & Mempelajari teknik dasar menabuh Suling Sunda lubang 6 \\
& Kecapi & Mempelajari teknik dasar menabuh Kecapi Cianjuran \\
& Rebab & Mempelajari teknik dasar menabuh Rebab Sunda \\
& Kendang & Mempelajari teknik dasar menabuh Kendang Sunda \\
& Gambang & Mempelajari teknik dasar menabuh Gambang Sunda \\
& Gamelan P/S & Mempelajari teknik dasar menabuh Gamelan P/S \\
& Gamelan Degung & Mempelajari teknik dasar menabuh Gamelan Degung \\
\hline
\end{tabular}




\begin{tabular}{|c|c|c|}
\hline \multicolumn{3}{|c|}{ Program Studi Seni Teater: } \\
\hline 1 & Olah Tubuh & $\begin{array}{l}\text { Melatih kelenturan tubuh melalui pemahaman organ tubuh de- } \\
\text { ngan cara memaksimalkan fungsinya. }\end{array}$ \\
\hline 2 & Olah Vokal & $\begin{array}{l}\text { Melatih teknik dasar penguasaan alat ucap seorang aktor teater } \\
\text { berkaitan dengan artikulasi, power vokal, intonasi dan diksi, } \\
\text { serta ekspresi. }\end{array}$ \\
\hline 3 & Kapita Selekta & $\begin{array}{l}\text { Memberikan pengayaan mengenai perkembangan teater masa } \\
\text { kini berdasarkan eksplorasi dan respon terhadap perkembangan } \\
\text { budaya. }\end{array}$ \\
\hline \multicolumn{3}{|c|}{ Program Studi Seni Kriya: } \\
\hline 1 & Batik & $\begin{array}{l}\text { Mempelajari teknik dasar membuat batik, serta pengetahuan } \\
\text { kesejarahan dan ciri khas batik berbagai daerah di Indonesia. }\end{array}$ \\
\hline 2 & Ornamen & Mempelajari ragam hias tradisi Nusantara. \\
\hline \multicolumn{3}{|c|}{ Program Studi Rias dan Busana: } \\
\hline 1 & Asesoris & $\begin{array}{l}\text { Mempelajari asesoris rias/busana tradisi dan modern, serta teknik } \\
\text { pembuatannya. }\end{array}$ \\
\hline \multicolumn{3}{|c|}{ Program Studi Angklung dan Musik Bambu: } \\
\hline 1 & Organologi & $\begin{array}{l}\text { Mempelajari teknik dasar pembuatan instrumen dan teknik } \\
\text { pelarasannya }\end{array}$ \\
\hline 2 & Angklung & Mempelajari ragam musik bambu dan teknik memainkannya. \\
\hline
\end{tabular}

Tabel 3

Kurikulum Prodi (pilih salah satu):

\section{Metode Pembelajaran Seni di STSI/ISBI Bandung}

Metode merupakan cara yang ditempuh untuk mencapai tujuan, sedangkan pembelajaran menurut Hawalik, (2003: 57) adalah suatu kombinasi yang tersusun meliputi unsur-unsur manusiawi, material, fasilitas, perlengkapan dan prosedur yang saling mempengaruhi untuk mencapai tujuan pembelajaran. Manusia terlibat dalam sistem pengajaran terdiri dari mahasiswa, guru, dan tenaga lainnya. Material, meliputi buku-buku, papan tulis dan kapur, fotografi, slide dan film, audio dan video tape. Fasilitas dan perlengkapan, terdiri dari ruangan kelas, perlengkapan audio visual, juga komputer. Prosedur meliputi jadwal dan metode penyampaian informasi, praktik, belajar, ujian dan sebagainya.

Berdasarkan penelusuran peneliti di lapangan, metode pembelajaran yang diberlakukan di STSI/ISBI Bandung menerapkan berbagai aplikasi metode pembelajaran, $\mathrm{di}$ antaranya: 1) ceramah dalam dua bahasa, biasanya disampaikan di awal perkuliahan sebagai pengantar. Porsinya tidak terlalu dominan karena proses pembelajaran yang dilaksanakan lebih banyak ke arah praktek; 2) diskusi dan tanya jawab berkaitan dengan fenomena budaya Indonesia dan kemungkinan mengembangkan kreativitas untuk berkolaborasi; 3) metode demonstrasi dan eksperimen, hal ini cukup menantang terutama untuk mata kuliah praktek seperti artistik make up, desain musik, pembuatan latar pertunjukan, desain kostum, dan lain-lain; 4) metode pengembangan kerja kelompok dalam proses menghasilkan karya bersama; dan 5) metode karya wisata/studi tour, mahasiswa diajak untuk melihat beraneka seni budaya Indonesia dengan mendatangi kantong-kantong seni.

\section{Hambatan Komunikasi Interkultural dan Solusi Pemecahan}

Kenyataan membuktikan bahwa orangorang yang datang dari budaya yang berbeda akan melakukan proses penerimaan 
dan pengolahan pesan sesuai dengan latar belakang budayanya. Hal ini seringkali berpotensi besar untuk terjadinya mispersepsi, miskomunikasi, bahkan missbehaviour. Cara paling bijaksana dan aman, langkah awal harus menanamkan sikap empatik. Setiap manusia pada dasarnya memiliki kebuda-yaan yang berbeda dan kita harus memiliki asumsi bahwa setiap orang akan berpikir dan bersikap berbeda pula. Dengan demikian, sejak awal kita bisa mengembangkan sikap toleransi.

Mengingat perkembangan teknologi komunikasi dan mobilitas manusia lintas budaya semakin menjadi, maka pergaulan yang melampaui batas-batas negara, etnik, dan budaya akan menjadi santapan seharihari terutama di kota-kota besar yang masyarakatnya sudah sangat heterogen dan multikultur. Dunia pendidikan misalnya, melalui program-program internasionalnya semakin gencar melakukan berbagai terobosan dan program yang salah satunya melalui pendekatan budaya. Tujuannya terutama untuk menunjukan jati diri bangsa di dunia internasional, maka pergaulan yang mendunia merupakan hal yang tak dapat dihindari.

Program Darmasiswa yang diselenggarakan Departemen pendidikan Indonesia dan diplomasi budaya Departemen Luar negeri merupakan contoh peristiwa interkultural yang diharapkan dapat berkontribusi terhadap tujuan yang lebih besar dalam menunjukan eksistensi Indonesia di dunia internasional yang berkaitan dengan kemajuan dunia pendidikan. Bagaimanapun keberhasilan setiap sub-sub program akan saling melengkapi untuk menghasilkan sesuatu yang sifatnya makro. Pelakupelaku program-program pemerintah yang mengemban tugas sebagai duta-duta atau komunikator-komunikator interkultural idealnya harus memahami betul bagaimana harus bersikap dan bertindak sehingga mencerminkan keluhuran budaya Indonesia di hadapan masyarakat internasiomal.
STSI Bandung jika dilihat dari aktifitas kelembagaannya sudah merupakan pelaku komunikasi internasional dan interkultural melalui pendidikan dan budaya. Setiap pelaku komunikasi interkultural jika ingin mendapatkan hasil maksimal maka harus memperbaiki cara berkomunikasinya. Berikut beberapa tip untuk melakukan komunikasi interkultural yang penulis kutip dari pendapat pakar komunikasi interkultural T. J. Wallis,

1. "Be Patient: Working in an intercultural environment can be a frustrating affair. Things may not get done when expected, communication can be tiresome and behavior may be inappropriate. Patience with yourself and others helps move beyond such issues and address how to avoid similar incidents in the future.

2. Establish Rules: Sometimes if working in a truly intercultural team it may be necessary for all to take a step back and set down some ground rules. i.e. how do we approach punctuality, meetings, communication, emails, disagreements, etc? It is always a good idea to try and develop the rules as a group rather than have them imposed.

3. Ask Questions: When you don't understand something or want to know why someone has behaved in a certain way, simply ask. Asking questions stops you making assumptions, shows the questioned you did not understand them and helps build up your bank of intercultural knowledge.

4. Respect: The foundation of all intercultural communication is respect. By demonstrating respect you earn respect and help create more open and fruitful relationships.

5. The Written Word: Sometimes people who do not have English as their mother tongue will read more proficiently than they speak. It is a good idea to always write things down as a backup.

6. Time: Not everyone in the world thinks "time is money". Understand that for many people work is low down on the priority list with things like family taking a much higher precedence. Do not expect people to sacrifice their own time to meet deadlines. It is good practice to always leave a bit of spare time when considering deadlines. 7. Humor: In an intercultural environment one man's joke is another's insult. Be wary of differences in the sense of humor and also the acceptability of banter and the like in a business environment.

8. Always Check: The easiest way of minimizing the negative impact of intercultural communication is to check and double check. Whether agreeing something or giving instructions, a minute 
spent double checking all parties are 'reading from the same sheet' saves hours of work later on down the line.

9. Be Positive: When faced with incidents of an intercultural nature steer clear of blame and conflict. Stay positive, analysis the problem areas and work as a team to build strategies and solutions to ensure the same never occurs again.

10. Self-Reflect: A good intercultural communicator not only looks outwards but also inwards. Take time to reflect on your own communication, management or motivation style and see where you can improve as an individual"1

Manusia pada dasarnya akan memiliki kemampuan untuk beradaptasi, tidak terkecuali dalam meningkatkan kemampuannya untuk melakukan komunikasi interkultural sesuai dengan konteks yang dihadapi. Hal ini dikemukakan oleh Wiseman (1995: 172-173) yang dilhami pemikiran Ruben \& J. Kim dkk yang mengasumsikan adanya suatu set system yang terbuka yang mengasumsikan mengenai kemampuan sifat dasar manusia untuk beradaptasi.

1. Asumsi pertama: Manusia secara inheren mengarahkan dirinya untuk beradaptasi dan tumbuh. Adaptasi merupakan tujuan hidup manusia yang fundamental yang dilakukan secara natural dan terus menerus.

2. Asusmsi kedua: Adaptasi terhadap suatu lingkungan sosial muncul melalui komunikasi. Perubahan adaptasi akan terus berlangsung selama mereka mengirim dan menerima pesan dalam lingkugan social budayanya.

3. Asumsi ketiga: Adaptasi merupakan proses yang kompleks dan dinamis. Seseorang dan lingkungannya akan bekerjasama dalam proses "take and give".

\section{PENUTUP}

Program Darmasiswa yang digalang Departemen Pendidikan Nasional RI merupakan salah satu program pendidikan melalui payung diplomasi budaya di antara negara-negara yang memiliki hubungan diplomatik dengan Indonesia. Program ini bertujuan untuk meningkatkan citra atau image positif Indonesia di mata dunia, meningkatkan kesepahaman, jalinan budaya dan pengertian di antara peserta, serta meningkatkan hubungan kerja antar negara. Selintas program ini terkesan sederhana, tetapi jika dilakukan secara profesional dan tepat akan memberi kontribusi signifikan dalam meningkatkan eksistensi Indonesia di dunia internasional. Program ini merupakan refleksi pergaulan interkultural yang di dalamnya syarat dengan berbagai keragaman budaya yang kemas melalui program pendidikan seni budaya.

Dewasa ini, tidak mungkin suatu negara mengisolasi diri terlepas dari pergaulan internasional maupun interkultural. Perkembangan teknologi komunikasi dan mobilitas manusia lintas budaya merupakan suatu fenomena yang tak dapat dihindari. Artinya manusia/masyarakat/suatu bangsa dewasa ini tidak dapat menutup diri dari pengaruh dan pergaulan global. Setiap detik serbuan beraneka informasi datang dan pergi memberi warna pada perubahan kehidupan manusia. Teknologi komunikasi berkontribusi signifikan dalam menjembatani pergaulan interkultural.

Lantas apa yang harus dilakukan? Menjadi manusia antarbudaya atau interkultural yang berada di tengah-tengah pergaulan dunia harus memiliki filter-filter yang kokoh agar tidak mudah tercabikcabik oleh pengaruh yang belum tentu sesuai dengan kepribadian bangsa. Ketat melakukan seleksi, cerdas dan bijak dalam menjalin interaksi serta kuatkan kepribadian dan kepercayaan diri bahwa bangsa Indonesia memiliki kearifan-kearifan lokal yang luhur dalam menjaga keseimbangan pergaulannya sehingga tetap menjadi salah satu bangsa yang diperhitungkan keluhuran martabatnya.

Program-program pemerintah berskala global yang digalakan sesungguhnya 
merupakan upaya menjadi bagian yang memberi andil dalam membentuk pergaulan dan kerjasama antar manusia atau antar negara tanpa harus meninggalkan jejak-jejak budaya yang melahirkannya. Oleh karena itu diplomasi budaya melalui program pendidikan merupakan program netral yang pelaksanaannya harus direspon positif berbagai kalangan, harus didukung, dan dibantu. Jadi melalui program kerjasama antar negara ini dapat membuka wawasan masyarakat Indonesia sehingga mampu mengimbangai berbagai fenomena secara lebih bijaksana. Ada ungkapan yang mengatakan bahwa dewasa ini "Kita harus berfikir secara global dan bertindak secara lokal". STSI/ISBI Bandung memiliki peluang besar membantu merealisasikan program-program besar bangsa melalui promosi dan pembelajaran seni sebagai unggulan materi ajarnya. Hal ini merupakan tantangan dan peluang karena seni telah diakui mampu menjadi media yang dapat menjembatani segala perbedaan budaya.

\section{Catatan Akhir}

${ }^{1}$ Sumber:http://www.colorado.edu/conflict/ peace/treatment/commimp.htm.

\section{Daftar Pustaka}

Alo Liliweri

2002 Makna Budaya dalam Komunikasi Antar Budaya. Jogjakarta: LkiS

Devito, Joseph

1991 Human Communication the Basic Course. New York: Harver Collins Publihers
Deddy Mulyana

2001 Komunikasi Antarbudaya. Bandung: Remaja Rosda Karya

Hamailk Oemar

2002 Psikologi Belajar Mengajar. Cet. III. Bandung: Sebar Baru Algensinso

Koentjaraningrat

1979 Pengantar Ilmu Antropologi. Jakarta: Aksara Baru

Jalaluddin Rakhmat dkk.

1993 Komunikasi Internasional. Bandung: Remaja Rosda Karya

Onong Uchyana Effendy

1992 Ilmu Komunikasi Teori dan Praktek. Bandung: Remadja Rosda Karya

Tjetjep Rohidi Rohendi

2000 Ekspresi Seni Orang Miskin. Bandung: Yayasan Nuansa Cendekia, Bandung

Saini KM

2001 Taksonomi Seni. Bandung: STSI Press

Wiseman, Richard

1995 Intercultural Communication Theory. London, New Delhi: Sage Publication

Yusmar Yusuf

1991 Psikologi Antar Budaya. Bandung: Remaja Rosda Karya, Bandung

Webtografi:

http://www.colorado.edu/conflict/peace/ treatment/commimp.htm. 